\title{
Ground Glass Hepatocyte
}

National Cancer Institute

\section{Source}

National Cancer Institute. Ground Glass Hepatocyte. NCI Thesaurus. Code C83011.

An abnormally large hepatocyte with eosinophilic or pale, glassy cytoplasm and

peripherally displaced nucleus. This appearance is due to hyperplasia of the smooth endoplasmic reticulum. 